\title{
Magangué y Mompox: conflictos territoriales, políticos y económicos entre provincias del Caribe colombiano, 1853-1875
}

Eloy A. Miranda Gil*

Recibido: diciembre de 2013

Aprobado: agosto de 2014

Resumen: En el presente artículo se intentan mostrar ciertas cosas que no se conocen de la historia política nacional, a nivel local, haciendo un análisis comparativo entre dos provincias del Estado Soberano de Bolívar en la segunda mitad del siglo XIX: Magangué y Mompox. Para ello, se mirará cómo se fueron conformando las relaciones clientelistas entre los diversos actores sociales influyentes de estas y en los diversos poblados emergentes del sector rural del Estado Soberano de Bolívar, que las conformaban. Estos vínculos permitían conformar unas pequeñas elites en los campos, las que a su vez tenían vínculos regionales y nacionales. También, está dirigido a señalar que esas relaciones se creaban para derrumbar el poderío de otra provincia, por consiguiente se generaban conflictos y rivalidades políticas, económicas, sociales y jurisdiccionales entre una y otra provincia.

Palabras claves: Conflictos provinciales, Magangué, Mompox, clientelismo, relaciones de poder, actores sociales.

\footnotetext{
* Historiador de la Universidad de Cartagena. Docente en Institución Educativa de San Isidro- Altos del Rosario (Bolívar, Colombia).elmigi69@hotmail.com
}

EL TALLER DE LA HISTORIA, vol. 6, n. ${ }^{\circ}$ 6, 2014, págs. 377-411. Issn: 1657-3633; e-Issn:2383-4794 Programa de Historia, Facultad de Ciencias Humanas, Universidad de Cartagena de Indias, Colombia 


\title{
Magangué and Mompox: territorial, political and economic conflicts between provinces of the Colombian Caribbean, 1853-1875
}

\begin{abstract}
This article is trying to show certain things that are not known national political history, at the local level, making a comparative analysis between two provinces of the sovereign State of Bolívar in the second half of the 19th century: Magangué and Mompox. Therefore be regarded relations patronage between different influential social actors and in the various emerging towns of the rural sector of the sovereign State of Bolívar, which consisted of them were how is complying. These links allowed to form a small elite in the fields, which in turn had regional and national links. Also, is aimed to point out that those relationships were created to cut down the power of another province, thus generated conflict and political, economic, social and territorial rivalries between one and another province.
\end{abstract}

Key words: provincial conflicts, Magangué, Mompox, patronage, power relations, social actors

\section{Presentación}

Las provincias de Magangué y Mompox han sido escasamente estudiadas por la historiografía nacional. De Magangué sólo se han preocupado historiográficamente: Eduardo Posada Carbó, en su texto El Caribe Colombiano. Una historia regional (1870-1930), ${ }^{1}$ el cual fue uno de los primeros libros de la academia que presentó a la ciudad de Magangué como el núcleo económico y social que fue para el período mencionado. Por otro lado, Cristian Roa Valdelamar, quien en su estudio sobre las ferias comerciales y ganaderas que se daban en esa población, muestra el desarrollo comercial que había alcanzado en la segunda mitad del siglo XIX ${ }^{2} \mathrm{Y}$ José Fernando Meneses en su tesis de pregrado examina el proceso histórico de la inmigración italiana en Colombia de finales del siglo XIX y comienzos del XX, centrándo-

1 Eduardo Posada Carbó, El Caribe Colombiano. Una historia regional (1870-1930), Bogotá, El Áncora Editores/Banco de la República, 1998.

2 Cristian Roa Valdelamar, Ferias comerciales de Magangué (1858-1902), Cartagena, tesis para optar título de historiador, Universidad de Cartagena, 2002. 
se en el estudio concreto y pormenorizado de su accionar socioeconómico en una ciudad intermedia como Magangué, entre los años de 1890 y 1930, uno de los muchos centros urbanos en los que se establecieron en el país y desde donde trataron de hacer la América en Colombia. ${ }^{3}$

De Mompox se puede encontrar una diversa historiografía, o más bien se hace referencia a la ciudad por sus gestas en la batalla de independencia y por la importancia que tuvo en la época colonial ya que servía de tránsito entre Cartagena y el interior del virreinato. ${ }^{4}$ Orlando Fals Borda en su interés por el descubrimiento de la historia de la región caribe, es quien más resalta la importancia de la ciudad en la vida política, económica y social del país y le dedica uno de sus tomos de su Historia Doble de la Costa. ${ }^{5}$

Pero, concerniente a las relaciones que se generaban entre estas dos provincias no existe ninguna investigación rigurosa. Solo encontramos el artículo realizado por Sergio Paolo Solano, Roicer Flórez y William Malkún, en donde hacen men-

3 José Meneses Urzola, Presencia e influencia italiana en Colombia: El caso de Magangué, 189o1930. Redes sociales y circuitos comerciales, Medellín, trabajo presentado para optar al título de Historiador, Universidad de Antioquia, 2009. Otros textos con referencia a la ciudad de Magangué son: Alfonso del Valle Porto, Compendio monográfico de la villa de Magangué, Medellín, 1992; Luis Striffler, El rio San Jorge Cartagena, 1958; Stella Salazar y Eduardo Aldana, "Magangué en la encrucijada", en Fabio Zambrano Pantoja, (comp.), Poblamiento y ciudades del Caribe colombiano, Bogotá, Observatorio del Caribe Colombiano/Fonade/Universidad del Atlántico, 2000; Carlos Uribe Uribe, Poblamiento y relaciones subregionales en el bajo Magdalena: Brazo de Loba, 177o1900, Medellín, Tesis de Historia Universidad Nacional, 2002; Francisco Balmaseda, "La feria de Magangué", en Boletín Historial n. ${ }^{4}$ 55-46, Cartagena, Academia de Historia de Cartagena, 1919; Orian Jiménez y Edgardo Pérez, La Mojana: medio ambiente y vida material en perspectiva histórica, Medellín, Universidad de Antioquia, 2007. Esta historiografía recalca y conmemora la profusión y el notable servicio que al país le prestaron las "veneradas" ferias, sin hacer un examen serio sobre el mismo. Nuestro interés no gira en torno a este tema, como si lo está el de Cristian Roa Valdelamar en su tesis de pregrado, por lo tanto no pretendemos hacer un estudio exhaustivo sobre el mismo, ya que nuestro interés es otro. En la tesis de pregrado de José Fernando Meneses Urzola, se precisan con más detalles la importancia que jugaron las ferias para el posterior desarrollo de la ciudad.

4 David Peñas Galindo y Oscar Arquez, Espacio, poblamiento y sociedad en la región de la depresión momposina, Medellín, Ed. Lealón, 1994; Javier Ocampo, Historia básica de Colombia, Bogotá, Plaza \& Janes Editores, 2007; "La patria Boba”, en Cuadernillos de Historia, Bogotá, Panamericana, 1998.

5 Orlando Fals Borda, Historia doble de la Costa. Mompox y Loba, Bogotá, Universidad Nacional de Colombia, 2002. 
ción a algunos de los conflictos de las provincias de Magangué y Mompox; ${ }^{6}$ sin embargo, no mostraron los actores sociales inmersos que generaban dichos conflictos en esas provincias ni la forma cómo y porqué se configuraron. Puesto que, su interés estaba dirigido, más que todo, a mirar las formas de ordenamiento territorial y generalizar sobre algunos factores y casos que determinaron los conflictos jurisdiccionales en el Bolívar Grande.7

Estos conflictos comenzaron a generarse debido al ascenso político, económico y social que venía ejerciendo Magangué en esa subregión (la depresión momposina), por lo tanto Mompox tuvo que afrontar y compartir el poder que en antaño ahí ejercía. ${ }^{8}$ Esto gracias a que, como lo señala el gobernador del Estado Soberano de Bolívar en 1858, Magangué era un importante punto comercial, debido a la desviación que tuvo el rio Magdalena por el Brazo de Loba e hizo de éste un puerto clave para el comercio, y porque para las compañías de navegación a vapor era más rentable el tráfico por este brazo. Además, ahí, se daban anualmente tres importantes ferias. ${ }^{9}$

Este auge hace que Magangué sea elevado a la categoría de provincia y es ahí cuando van a tomar fuerza los conflictos entre estas dos provincias. ${ }^{10}$ Debido a que no logran definirse con claridad los limites jurisdiccionales que las separan, y, por un lado, la organización de las provincias, por el otro, la expansión de los hatos ganaderos hicieron que se disputaran los territorios; ya que entre más terrenos se

6 Sergio Paolo Solano, Roicer Flórez y William Malkún, "Ordenamiento territorial y conflictos jurisdiccionales en el Bolívar Grande 1800-1886”, en Historia Caribe n. ${ }^{\circ} 13$, Barranquilla, Universidad del Atlántico, 2008, pp.65-119.

7 En otros de sus artículos, ellos, señalan el papel prominente que tuvieron los ganaderos y los comerciantes en el Estado Soberano de Bolívar, ver: Sergio Paolo Solano, Roicer Flórez y William Malkún, "Ganaderos y comerciantes: el manejo del poder político en el Estado Soberano de Bolívar (Colombia), 1857-1886”, en Historia y Sociedad n. ${ }^{\circ} 18$, Medellín, Universidad Nacional de Colombia, 2010, pp.15-42.

8 S. P. Solano, R. Flórez y W. Malkún, “Ordenamiento territorial y conflictos”, p.91.

9 C. Roa Valdelamar, Ferias comerciales de Magangué; A. del Valle, Compendio monográfico de la villa, p.77; L. Striffler, El rio san Jorge.

10 Eloy Miranda Gil, Disputas territoriales, políticas y económicas entre las provincias de Magangué y Mompox, 1853-1875, Cartagena, trabajo de grado para optar al título de historiador, Universidad de Cartagena, 2013. Ver el segundo capítulo, pp.71- 101. 
tiene o se acapare, más poder económico-político se va a ejercer en la provincia y para la provincia. Dado que, quien tiene más tierra, tiene más poder. Esto le permitirá a cualquier actor social ejercer un dominio en la provincia y enaltecer el papel de ella ante las demás. Por consiguiente, se van a aumentar y a configurar las disputas y/o conflictos entre estos dos: Magangué y Mompox. En este orden de ideas, el presente artículo girará en torno al siguiente cuestionamiento: ¿De qué manera se configuraron las rivalidades territoriales, políticas y económicas entre las provincias de Magangué y Mompox? ¿Por qué y cómo se daban dichas rivalidades?

En otras palabras, este trabajo muestra ciertas cosas que no se conocen de la historia política nacional, a nivel local, en donde se hace un análisis comparativo entre dos provincias del Estado Soberano de Bolívar en la segunda parte del siglo XIX: Magangué y Mompox. Para ello, se miraran las relaciones clientelistas entre los diversos actores sociales influyentes de estas y en los diversos poblados emergentes del sector rural del Estado Soberano de Bolívar, que las conformaban. Estos vínculos permitían conformar unas pequeñas elites en los campos, las que a su vez tenían vínculos regionales y nacionales. ${ }^{11}$

Argumento que mediante la articulación económica regional se presentaron lazos interprovinciales (entre provincias) e intraprovinciales (lazos que se presentaron al interior de la provincia) que permitieron consolidar vínculos entre pequeños y medianos productores de un centro urbano o rural ${ }^{12}$ (o de la elite de ese núcleo) y con alguna facción política que los apoyara $-\mathrm{y}$ de paso, ésta, podría aumentar su

11 Por otra parte Hermes Tovar nos ha influenciado a hacer esta investigación puesto que “... la provincia (de Cartagena) como objeto de relaciones sociales y económicas y como red de poblados y ciudades subsidiarias espera aún un esfuerzo minucioso de investigación histórica”, ver: Hermes Tovar, "La historiografía sobre Cartagena de indias en el siglo XVIII", en Haroldo Calvo y Adolfo Meisel (eds.), Cartagena de indias y su historia, Cartagena, Universidad Jorge Tadeo Lozano, Seccional Caribe y Banco de la República, 1997. A nosotros más que esas relaciones entre provincias nos interesan, más que todo, los desencuentros que habían entre ellas, es decir las relaciones de conflictos que las caracterizaron entre 1853 y 1875.

12 Roicer Flórez señala que esta articulación se debió en gran medida al negocio de la destilación y rectificación de aguardientes debido a que los comerciantes, montados en sus burros y mulas y a través de trochas y caminos de herraduras, llegaban a los lugares más apartados de la geografía regional para abastecer de licores a cada uno de los caseríos del Estado. Roicer Flórez, "Caña de azúcar y aguardiente en el Estado Soberano de Bolívar, 1857-1886”, en Cuadernos de Desarrollo Rural n. ${ }^{\circ} 6$, Bogotá, Universidad Javeriana, 2009, pp.35-57, 48. 
representatividad ahí- para luchar contra las elites de otras provincias; estas relaciones se dieron gracias a los flujos económicos, creándose vínculos provinciales que se disponían a mejorar el poder de sus centros urbanos o provincias y, en ese sentido, desmoronar el poderío de otros más fuertes o, en el menor de los casos, para sobresalir ante el Estado. Todo ello, debido a los cambios introducidos en la política de los radicales, por consiguiente, se fueron generando inquietudes en el imaginario de las gentes del sector rural, con respecto a la política.

De esta manera, pretendemos contribuir en el análisis de la cultura política de los actores sociales que impulsaban dichas rivalidades y que podrían generar traumas en la conformación del Estado-Nación. El método prosopográfico nos sirvió de gran ayuda al momento de la selección de las personalidades de ambas partes y los vínculos que estos establecían en cada provincia para entrar en rivalidad con la otra. ${ }^{13}$

La estructura que conformará este artículo será de la siguiente forma: primero, identificaremos las personalidades de ambas provincias y su estructura, es decir, ¿Quiénes eran? ¿Por qué fueron escogidos? ¿Cómo fueron escogidos? ¿A qué se dedicaban? ¿Cuáles eran los más importantes? Y segundo, distinguiremos los conflictos territoriales y/o jurisdiccionales, políticos y económicos que presentaron las provincias de análisis, y en cada uno de ellos demostraremos como sus elites ponían a funcionar su poder (político y económico) para actuar en beneficio propio y para su provincia y, en contraposición de la otra. Esto es, como actuaron en torno a los conflictos interprovinciales: como arremetían los momposinos y, en consecuencia, como se defendían los magangueleños, y/o a la inversa; cuáles eran sus articulaciones políticas, económicas y sociales.

13 Ver Peter Burke, Venecia y Ámsterdam. Estudio sobre las elites del siglo XVII, Barcelona, Gedisa Ed., 1996, p.16; Úrsula Vones-Liebenstein, "El método prosopográfico como punto de partida de la historiografía", en Anuario de Historia de la iglesia n. ${ }^{\circ}$ 14, Navarra, Universidad de Navarra, 2005, pp.351-364. 


\section{Los notables de las provincias de Magangué y Mompox}

El mayor problema con que afrontamos al hacer un estudio de este tipo es el de identificar a las elites, ${ }^{14} \mathrm{y}$ en nuestro caso, las de las dos provincias es aún más difícil distinguirlas debido a los problemas que subyacen al Caribe colombiano al momento de adquirir documentos de siglos pasados, puesto que estos no son conservados de la mejor manera y por ende son víctimas de avatares que llevan a su destrucción. ${ }^{15}$ No obstante con el material que contamos podemos aproximarnos a hacer un estudio de esta categoría en las dos provincias aquí objeto de análisis.

Entre 1853 y 1875 las provincias de Magangué y Mompox experimentaron la formación, configuración y consolidación de unas elites locales con una alta capacidad para gobernar a nivel local y regional, ${ }^{16}$ y quizás a nivel nacional, y contaban con los criterios de rango, riqueza y poder que les permitirán establecer los diferentes vínculos provinciales al momento de la resolución de un conflicto interprovincial.

Estos grupos actuaron de acuerdo a su cultura política tradicional ${ }^{17}$ que se fortalecía mediante diversos vínculos familiares, matrimoniales, económicos, de partido, de amistad, de clientela, etc. A través de los cuales ponían a funcionar unas prácticas sociales que al interior de ellos las podríamos definir teniendo en cuenta los parámetros de Pierre Bourdieu, quien puntualiza que son las "aptitudes que se adoptan para moverse, actuar y orientarse según la posición ocupada en el espacio social, según la lógica del campo y de la situación en la cual se está comprometi-

14 P. Burke, Venecia y Ámsterdam. Estudio sobre las elites del siglo XVII.

15 Romana Falcón, "Un diálogo entre teorías, historias y archivos", en Romana Falcón (coord.), Culturas de pobrezas y resistencia. Estudios de marginados, proscritos y descontentos México, 1804-1910, El Colegio de México/Universidad Autónoma de Querétaro, 2005, pp.11-42.

16 S. P. Solano, R. Flórez y W. Malkún, “Ordenamiento territorial y conflictos”, pp.65-119.

17 François-Xavier Guerra, "Lugares formas y ritmos de la política moderna”, en Boletín de la Academia Nacional de la Historia n. ${ }^{\circ}{ }^{285}$, Caracas, Academia de la Historia de Venezuela, 1989, p.8; Margarita Garrido, Reclamos y representaciones. Variaciones sobre la política en el Nuevo Reino de Granada, 1770-1815, Bogotá, Banco de la Republica, 1993, 414 págs. 
do". ${ }^{18}$ Las prácticas de estas dos elites se llevaron a cabo tanto en las oficinas, en las casas de los hacendados o en sus mismas haciendas, donde planificaron las estrategias y alianzas políticas y económicas en torno a la resolución de algún conflicto interprovincial, así como también acaecieron en los territorios en disputa, tal como lo veremos más adelante.

La elite de Mompox, por ejemplo, era de una raigambre más tradicional que la de Magangué puesto que tenía miembros que eran herederos de las costumbres colonialistas, es decir, algunos de ellos eran hijos de los mártires de la independencia de esa ciudad los cuales se beneficiaron de ese acontecimiento. Tal es el caso de los Gutiérrez de Piñeres, los Martínez Troncoso, los Herreras y los Ribón, quienes conformarían los grupos familiares que Fals Borda cataloga como la "burguesía comercial urbana tradicional", los que se dedicaban a la explotación de las haciendas ganaderas y al comercio. ${ }^{19}$

Pero en la segunda mitad de esa centuria la elite momposina sufrió una reconfiguración en sus formas de actuar. Debido a que tuvo que compartir el poder político y económico que había ejercido en esa zona. Compartirlo, no sólo con la naciente elite de su provincia rival, sino también con la que venía in crescendo en su interior ${ }^{20}$. Por lo que, algunos de sus actores sociales actuaron en pro de sus intereses personales que en ultimas terminaría afectando los de la provincia, o en su defecto, beneficiándola.

18 Alicia Gutiérrez, Las prácticas sociales: una introducción a Pierre Bourdieu, Madrid, Tierradenadie, 2002, p.73.

19 Orlando Fals Borda, El Presidente Nieto, Bogotá, Universidad Nacional/Banco de la República/El Áncora Editores, 2002.

20 Esto porque la segunda mitad del siglo XIX colombiano presenció la aparición de un nuevo grupo de políticos ligados a una economía de exportación basada en el tabaco, la ganadería y otros productos que adquirieron una demanda internacional; así como también, a la intromisión de un modo de producción campesino que amplío la frontera agrícola, el trabajo libre y asalariado y una creciente demanda de medios de transporte para beneficiar la producción de nuevos artículos y en mayor cantidad, lo que permitió el reemplazo del viejo modo de producción colonial basado en el latifundio. Ver: E. Posada. El Caribe colombiano; José Ocampo, Colombia y la economía mundial 183o1910, Bogotá, Siglo XXI Eds., 1984, 459 págs.; Grey Vérbel, "Elites y redes de poder en torno al proyecto regenerador. Cartagena, 1874-1892", en El Taller de la Historia n. $^{\circ} 3$, Cartagena, Universidad de Cartagena, 2011, pp.41-62. 
El cúmulo de estos nuevos políticos momposinos que aprovecharon las ideas del liberalismo para consolidarse en las posiciones más importantes del poder político local fueron los pertenecientes a las viejas familias preponderantes de la villa y a las que comenzaron a engrosar estas filas. Por ejemplo, los hermanos Manuel y Pedro Laza Grau, ${ }^{21}$ Pedro Tiberio Esparragoza, ${ }^{22}$ Juan Rives Miranda, ${ }^{23}$ Juan Castellanos, ${ }^{24}$ Abelardo Covilla, ${ }^{25}$ José Beatriz Trespalacios, ${ }^{26}$ Segundo y Sabas Martínez Troncoso, ${ }^{27}$ Juan Ballesteros, ${ }^{28}$ Isidoro Salas, Gabriel del Villar Gutiérrez de Piñeres, Julian J. Berrio, Vicente Flores, Pedro Salcedo del Villar, Pedro Blanco García, los hermanos Ribón, quienes se ubicaron en los diferentes espacios del poder político de la provincia, entre otros.

21 Biblioteca Bartolomé Calvo [ввс], colección de prensa microfilmada, Gaceta Oficial del Estado Soberano de Bolívar, Cartagena, marzo 23 de 1862, mayo 25 de 1862, agosto 10 de 1862 y 17 de agosto de 1862; Gaceta Oficial del Estado Soberano de Bolívar, Cartagena, enero 19 de 1863, noviembre 8 de 1863; Gaceta de Bolívar, Cartagena, noviembre 18 de 1866, la prensa aquí citada fue consultada en esta colección de microfilms.

22 BBC, Gaceta de Bolívar, Cartagena, julio 03 de 1859; Gaceta de Bolívar, Cartagena, agosto 25 de 1861; Gaceta de Bolívar, Cartagena, agosto 17 y septiembre 7 de 1862; Gaceta de Bolívar, Cartagena, 1868 .

23 BBC, Gaceta Oficial del Estado Soberano de Bolívar, Cartagena, agosto 7 de 1859; Gaceta Oficial del Estado Soberano de Bolívar, Cartagena, agosto 25 de 1861; Gaceta Oficial del Estado Soberano de Bolívar, Cartagena, enero 24 de 1864; Gaceta de Bolívar, Cartagena, Julio de 1866; Gaceta Oficial del Estado Soberano de Bolívar, Cartagena, 15 de junio de 1865.

24 BBC, Gaceta Oficial del Estado Soberano de Bolívar, Cartagena, agosto 17 y septiembre 7 de 1862; Gaceta Oficial del Estado Soberano de Bolívar, Cartagena, junio 15 de 1865 y agosto 24 de 1865; Gaceta de Bolívar, Cartagena, marzo 25 de 1866.

25 BвC, Gaceta Oficial del Estado Soberano de Bolívar, Cartagena, septiembre 7 de 1862; Gaceta Oficial del Estado Soberano de Bolívar, Cartagena, enero 24 de 1864; Gaceta de Bolívar, Cartagena, 1873 y 1874 .

26 BвC, Gaceta Oficial del Estado Soberano de Bolívar, Cartagena, septiembre 7 de 1862; Gaceta del Estado Soberano de Bolívar, Cartagena, 20 de septiembre de 1863; Gaceta de Bolívar, Cartagena, julio 22 de 1866; Gaceta de Bolívar, Cartagena, noviembre 8 de 1866; Gaceta de Bolívar, Cartagena, 1870.

27 BBC, Gaceta del Estado Soberano de Bolívar, Cartagena, noviembre 15 de 1863; Gaceta del Estado Soberano de Bolívar, Cartagena, agosto 24 de 1865; Gaceta del Estado Soberano de Bolívar, Cartagena, enero 24 de 1864 y mayo 8 de 1864.

28 BBC, Gaceta del Estado Soberano de Bolívar, Cartagena, mayo 8 de 1864; Gaceta Oficial del Estado Soberano de Bolívar, Cartagena, abril 2 de 1865; Gaceta de Bolívar, Cartagena, 1870. 
Hay que tener presente, primero, que ésta elite sufrió quebrantos a principios de la década de los años sesenta del siglo XIX, puesto que perdió algunos de sus más altos miembros ${ }^{29}$ en las guerras civiles que azotaron el país y consecuencia de ello, otros se vieron obligados a huir de la ciudad para proteger sus bienes. En ese sentido, la elite momposina queda un poco resquebrajada en nuestro periodo de estudio.

Y segundo, que al interior de la elite momposina había divisiones políticas, que generaban discordias internas, por ejemplo se presentaron varios choques entre las facciones políticas de la villa. En 1840 año en que se presentó la Guerra de los Supremos a nivel nacional, en Mompox se libró un conflicto entre los Ribón y los Martínez Troncoso. Los primeros ministeriales, seguidores de la campaña de Mosquera y Herrán, y los segundos oposicionistas liberales de la facción de Carmona y Obando. ${ }^{30}$ En 1857 hubo un conflicto político-social en la ciudad entre los habitantes del barrio abajo liderados por el gobernador de la provincia y los habitantes del barrio arriba, estos hechos fueron auspiciados por los dos partidos políticos tradicionales que empezaban a gestarse en el país y que comenzaban a ganar terreno en la ciudad. ${ }^{31}$

En 1865 la renuncia del gobernador de la provincia demuestra otra discordia entre él y las personalidades de la provincia que integraban el concejo municipal, siendo la mayoría de estos, comerciantes, quienes se negaron a acatar la ley sobre los impuestos comercial, el de cría, levante y degüello de ganado y el impuesto agrario, ${ }^{32}$ por considerarla un abuso, ya que la provincia debía contribuir con la suma de \$7000,oo. Juan Rives Miranda, decidió renunciar porque su “... conducta digna e intachable no era del agrado de los señores notables de ese lugar, los que a falta de hechos que censurar, se valían de intrigas y falsedades para desprestigiar mi administración”.

Un año después se presentó otro "choque de trenes" al interior de la elite momposina entre el gobernador de la provincia, Juan Castellanos y el administra-

29 Uno de esos casos fue el fallecimiento del Capitán Andrés Gómez.

30 O. Fals Borda, El Presidente Nieto, pp.65A y 71B.

31 BвC, Gaceta Oficial del Estado de Bolívar, Cartagena, febrero 27 de 1859.

32 BBC, Gaceta Oficial del Estado de Bolívar, Cartagena, junio 24 y julio 6 de 1865. 
dor del tesoro municipal, José Beatriz Trespalacios, ${ }^{33}$ quien se opuso a la visita que el gobernador quería hacer a la oficina del tesoro municipal porque, según él, era algo que le correspondía exclusivamente al concejo municipal,

...dictar las disposiciones convenientes para la administracion, recaudación, contabilidad e inversión de las rentas del distrito, únicos objetos o ramos a cargo de esta oficina, aquella corporación [el concejo municipal] no ha dado injerencia en ellos a la gobernación, i por consiguiente el empleado encargado de la oficina no tiene el deber de prestarse a ser visitado por los que no tengan facultad legal para ello.

Estas intestinas discordias dan para pensar en la heterogeneidad de la elite momposina, puesto que al interior de la provincia cada quien pugnaba por sus intereses personales y clientelares; empero, al momento de presentarse los conflictos interprovinciales unían sus fuerzas para arremeter a favor de los intereses de la provincia, y en contra de quien quisiera desfavorecerla, por lo tanto, existía cierta consolidación y homogeneidad como elite tradicional que la caracterizaba.

De otro lado, la elite magangueleña no estaba tan consolidada como la de Mompox, pero estaba en proceso de formación y consolidación. Porque Magangué era una naciente ciudad y en crecimiento y este crecimiento lo obtiene gracias, en primer término, al movimiento comercial que ahí se ejercía desde las décadas del cuarenta del siglo XIX y se va a afianzar con sus ferias dos décadas después; ${ }^{34}$ en segundo lugar, a la desviación que toma el rio Magdalena a mediados de esa centuria, que lo convierte en un puerto esencial de intercambio, acopio y redistribución comercial, en donde laboraban un sinfín de personas de toda índole en diversas actividades relacionadas con el comercio, tales como, la boga, el leñateo, el hospedaje, el suministro de alimento a los viajeros y comerciantes, etc.; y a la explotación de su hinterland, a través de la producción y comercialización del ganado, la quina, la tagua, las maderas, el tabaco, el arroz, la caña de azúcar, entre otros. ${ }^{35}$

33 BвC, Gaceta de Bolívar, Cartagena, julio 22 de 1866.

34 S. Salazar y E. Aldana, "Magangué en la encrucijada”, p.218.

35 J. Meneses Urzola, Presencia e influencia italiana, pp.135-137. 
Este desarrollo va aunado a una paralela inmigración de ciudadanos nacionales y extranjeros, quienes van a ver crecer sus riquezas en esa ciudad y sus alrededores y, por consiguiente, terminan defendiendo los intereses de ella y de la provincia al momento de presentarse los conflictos interprovinciales con su provincia vecina. Porque ahí están en juego sus haberes personales. Por ende, crean nexos, al igual que sus rivales, para defenderse o para embestir.

En Magangué se asentó una buena parte de esta nueva clase de ciudadanos con capacidad especulativa que venía creciendo en el país, así como de ciudadanos extranjeros, especialmente de italianos. ${ }^{36}$ Algunos de los apellidos de estos foráneos establecidos en Magangué para la década de los sesenta encontramos a los Drago, Gracia, Paniza, Peñarredonda, Molinares, Pianeta, Mangones, de la Espriella, entre otros. "Los núcleos familiares que formaron eran representantes notables dentro del mundo social local, participando activamente como negociantes e incluso en el mundo de la política municipal del último tercio del siglo XIX". ${ }^{37}$ Por ejemplo, Manuel Drago y J. D. Paniza fueron gobernadores de la provincia. 38

Entre otras familias importantes de la provincia de Magangué encontramos a los Pacheco, Cárcamo, Arango, García, Vides, Comas, Viñas, etc. ${ }^{39}$ Algunas de las cuales combinaron la política, el comercio, la ganadería y la agricultura. Ejemplo de ello tenemos el caso de Juan Bautista García Baltazar, comerciante, juez, administrador de hacienda de la provincia, etc. ${ }^{40}$ Otro craso ejemplo es el de Ventura García, quien fue comerciante, dueño de un aparato destilatorio, diputado por la pro-

\footnotetext{
36 Eduardo Posada, "Empresarios y ganaderos en la Costa Atlántica (1850-1950)", en Carlos Dávila (comp.), Empresas y Empresarios en la historia de Colombia. Siglos XIX-XX. Una colección de estudios recientes, Bogotá, Editorial Norma, 2003, p.68; J. Meneses Urzola, Presencia e influencia italiana, 260 págs.

37 J. Meneses Urzola, Presencia e influencia italiana, p.101.

38 "Informe anual del Gobernador de la provincia de Magangué", en Archivo Histórico de Cartagena [AHC], Gaceta de Bolívar, Cartagena, octubre 25 de 1873; AHC, Manuscritos, Sección Provincias [SP], fondo gobernación [FG], Caja n. ${ }^{\circ} 38$, noviembre 24 de 1873.

39 G. Vérbel, "Elites y redes de poder", pp. 41-62; S. Solano, W. Malkún y R. Flórez. "Ganaderos y comerciantes", pp.15-42.

40 BвC, Gaceta Oficial del Estado Soberano de Bolívar, Cartagena, junio 18 y 25 de 1865 .
} 
vincia, fiscal y gobernador; ${ }^{41}$ Eduardo Cárcamo, quien ofició como diputado por la provincia y gobernador de la misma. ${ }^{42}$ Entre otros tenemos a: José del Carmen $\mathrm{Bu}-$ la, Pedro Argumedo, Joaquín Cárcamo Berrio, Pedro Regalado Porto, Antonio K. Pacheco, Fernando Cárcamo, Carmelo Arango, Andrés Gutiérrez, Manuel Urueta, Francisco Vides, a quienes podemos encontrar ocupando las diversas esferas del poder local en la provincia y para la provincia, entre 1853 y 1875.

Es decir, la mayoría de los personajes que hemos seguido en esta investigación es porque alguna vez -en nuestro periodo de estudio- actuaron en la política local y regional, en la vida comercial de la provincia o fueron ganaderos y agricultores, ó, tuvieron relaciones de cualquier clase (de compadrazgo, de amistad, de clientela, de parentesco, etc.) con alguno de aquellos.

Por otra parte, el censo levantado en el año de 1870 en el Estado Soberano de Bolívar muestra algunas características de la sociedad de cada una de las provincias del Estado y las ocupaciones de sus miembros, también nos ofrece los datos aproximados de la población de cada una de ellas. ${ }^{43}$ En cuanto a las provincias de Magangué y Mompox encontramos que Magangué a pesar de haber adquirido ese auge del que hemos hablado anteriormente, su población total era de 16.946 habitantes y estaba entre las menos pobladas del Estado, ${ }^{44}$ además era la provincia más pobre de todo el Estado y, como lo muestra Roicer Flórez, “...en Magangué era muy

41 BBC, Gaceta de Bolívar, Cartagena, agosto 12 de 1866; "Informe anual del gobernador de la provincia de Magangué", en AHC, Gaceta de Bolívar, Cartagena, agosto 7 de 1870; "Informe anual del Gobernador de la provincia de Magangué", en AHC, Gaceta de Bolívar, Cartagena, agosto 13 de 1871; Diario de Bolívar, Cartagena, 1878 y septiembre 6 de 1881.

42 BBC, Gaceta de Bolívar, Cartagena, septiembre 19 de 1872; Gaceta de Bolívar, Cartagena, 1874.

43 BвC, Gaceta de Bolívar, Cartagena, Mayo 9 de 1871; septiembre 10 de 1871; febrero 5 y 12 de 1871; marzo 12 de 1871; enero 7, 8 y 22 de 1871; febrero 4 de 1872; marzo 17 de 1874.

44 Debemos tener en cuenta que Magangué tuvo un incremento en su población casi al 100\% en los últimos 20 años, pero ese incremento no le bastó para alcanzar una mejor posición entre las provincias de 1870. En cambio Mompox en esos veinte años tuvo una tendencia a la baja en su población, o más bien esta se estancó. Ver: Biblioteca Luis Ángel Arango [BLAA], Gaceta de Bolívar, Cartagena, febrero 5 y mayo 9 de 1871; BBC, Gaceta Oficial del Estado de Bolívar, Cartagena, octubre 9 de 1859; BвC, Gaceta Oficial del Estado de Bolívar, Cartagena, Marzo 7 de 1860; BBC, Gaceta Oficial del Estado Soberano de Bolívar, Cartagena, Mayo 7 de 1865; Gaceta de Bolívar, Cartagena, febrero 5 y mayo 9 de 1871. Cabe mencionar que estas provincias se vieron afectadas por los feroces ataques del Cólera y otras enfermedades que se propagaron en el Caribe colombiano en las décadas de 1850 y 1860, de ahí la disminución presentada. 
reducido el número de ciudadanos que tenían la cantidad de $\$ 300$,oo anuales establecido por el Estado para cancelar el impuesto sobre la renta”. ${ }^{45}$

La población económicamente activa (PEA) de la provincia de Magangué equivalía a 6328 habitantes, aproximadamente, es decir el 37.3\% de la población total de la provincia. Ahora bien, los comerciantes, los ganaderos y los agricultores alcanzaban el $76 \%$ de la PEA de la provincia y el $28.3 \%$ de la población total de la misma, representados en 4812 habitantes de los cuales 4641 se dedicaban a la agricultura (ver tabla 1).

Tabla 1: Porcentaje de las ocupaciones, provincias de Magangué y Mompox 1870

\begin{tabular}{|c|c|c|c|c|c|c|c|c|c|c|}
\hline 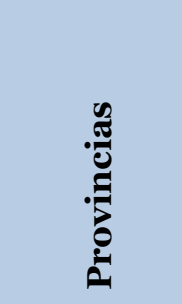 & 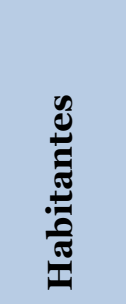 & 㽞 & 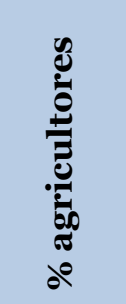 & 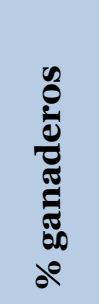 & 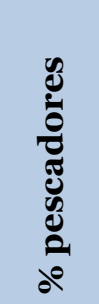 & 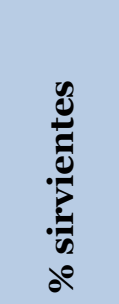 & 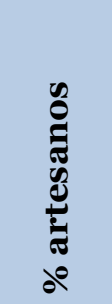 & 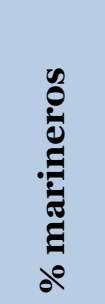 & 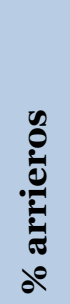 & 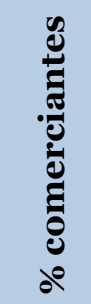 \\
\hline Magangué & 16.946 & 6328 & $73.3 \%$ & $1.5 \%$ & $0.7 \%$ & $7.6 \%$ & $5.8 \%$ & $1.6 \%$ & - & $1.2 \%$ \\
\hline Mompox & 22.499 & 8100 & $65.3 \%$ & $2.6 \%$ & $3 \%$ & $13.6 \%$ & $9.8 \%$ & $0.4 \%$ & - & $1.4 \%$ \\
\hline
\end{tabular}

Fuente: BLAA, Gaceta de Bolívar, Cartagena, 5 de febrero y 9 de mayo de 1871.

Otro tanto sucedía en su provincia rival. Mompox era una provincia densamente más poblada que Magangué, ocupando el sexto lugar en el Estado con una población de 22.499 habitantes aproximadamente, y con una PEA de 8100 correspondiente al $36 \%$ de la población total de la provincia. En ésta, el grupo de ganaderos, comerciantes y de agricultores fue superior a sus ejemplares de la provincia de Magangué, donde el grupo de ganaderos momposinos duplicaba a los de aquella. La suma total de estos tres grupos alcanzaba el 69.3\% con relación a la PEA de la provincia momposina y un $25 \%$ aproximadamente con respecto a la población de toda la provincia, esto es, 5618 habitantes aproximadamente.

45 R. Flórez, "El sistema de arrendamiento”, p.18. 
En suma, el censo nos permite descubrir la cantidad de ganaderos, comerciantes y agricultores que tenían ambas provincias. Hecho que nos da para pensar en una cantidad interesante de personajes para estudiar en esta investigación, ya que si sumamos los grupos de ambas provincias nos encontramos con un resultado bastante considerable: de 10.430 habitantes, de los cuales 9932 eran agricultores. Empero, si tenemos en cuenta que la mayoría de la población del Estado era analfabeta y que de estos 9932 agricultores que existían en estas dos provincias la mayoría eran pequeños y medianos productores que no sabían leer y escribir, los cuales dejaron pocos datos (o ningún dato) acerca de sus actuaciones en la vida política, social y económica (a menos de que contaran con un escribiente o fueran mencionados en algún conflicto social o político ó, tuvieran poder e influencia política) verbigracia: Julián Vera, Pedro A. Cerpa, Crispín Viañas, Juan Bernardo Vilches, entre otros. ${ }^{46}$ Por consiguiente, es poco probable contar con este grupo tan amplio de habitantes, pues, porque es difícil reconstruir sus vidas y sus redes en los archivos.

De los ganaderos y los comerciantes, que eran cerca de 498 habitantes, también podemos omitir cierta cantidad de ellos por algunas de las características que presentaba el Estado (analfabetismo, pobreza, concentración del poder en pocas manos, etc.). Además, porque era casual no solo en estas provincias, sino también en el Estado, que algunas de las familias notables combinaran ciertas prácticas (la ganadería, la agricultura y la política) como ya lo hemos mencionado. De ahí que, el grupo a tener presente sea muy reducido.

\section{2.- Conflictos entre las provincias de Magangué y Mompox. Articulación y estrategias políticas ante dichos conflictos, $1853-1875$}

Los conflictos que se presentaron en este periodo entre las provincias de Magangué y Mompox fueron: los territoriales, acaecieron por territorios que se encontraban en los límites fronterizos de estas, ya que esas delimitaciones no estaban definidas con claridad; y por distritos que dada la lejanía con la capital de la provincia podrían estar en diferente proceso de acaparamiento por la otra, debido a la aparente

46 BBC, Gaceta de Bolívar, Cartagena, agosto 23 y diciembre 6 de 1868. 
debilidad que tenían los dirigentes de la provincia para llegar a los lugares más recónditos de la misma y ejercer su autoridad, esta aparente debilidad la aprovechaban los de las provincias más cercanas para intentar acaparar esos territorios 47. Estos también podrían ser conflictos económicos, si tenemos en cuenta que quien tiene más tierra, tiene más poder.

Los políticos, se dieron porque los momposinos querían monopolizar el poder político de la depresión (haciendo las veces para suprimir la provincia de Magangué). Los económicos, acaecieron por las disputas comerciales (Mompox quería volver a ser el emporio comercial de la zona) y por los acaparamiento de las tierras (en donde no se respetaban los límites establecidos por el Estado, puesto que eran confusos). En torno a estos conflictos miraremos el modo de actuar de las personalidades de ambas provincias. En suma, analizaremos la manera como se configuraron las disputas territoriales, políticas y económicas entre las provincias de Magangué y Mompox, entre 1853-1875.

\subsection{Conflictos territoriales y/o jurisdiccionales}

En 1860 el gobernador de la recién creada provincia de Magangué envía una carta al Secretario General del Estado Soberano de Bolívar quejándose de su similar de Mompox, porque este llamó a su jurisdicción a uno de sus distritos, veamos los apartes de esta nota a continuación:

Como por lo resuelto por esa secretaria en fecha 31 de enero último $\mathrm{N}^{\circ} 6$, lo fuese solo en abstracto, a la recaída en una nota pasada por esta prefectura en 3 del mismo mes bajo el $\mathrm{N}^{\circ}$ 3, correlacionado al distrito de Majagual como comprendido este al extinguido departamento de Magangué, i que el de Mompos, lo llamó a la vez sujeto a su jurisdicción; también esto ha dado lugar a [que] esta gobernación haya tenido que volver a llamar la atención de esa secretaria para que se sirva declarar pues que aquel distrito desde la creación del nuevo departamento de Magangué, el distrito de Majagual fue anexado á este según el decreto de su creación; pues esto mismo sirve de rémora a la gobernación i aun a la administración de hacienda para su reglamentación, pues al hacerse como debe a aquellos empleados i manejadores de rentas serias exigencias se evaden

47 S. P. Solano, R. Flórez y W. Malkún, “Ganaderos y comerciantes”, p.33. 
con respuesta evasivas, diciendo dieron cuenta de su manejo á aquellas autoridades porque así se lo previnieron.

Y como el infrascrito satisfecho como lo está que el distrito de Majagual pertenece á el departamento de Magangué ha prevenido en este sentido haciendo responsables a aquellos funcionarios por su conducta tenida en la presente cuestión. ${ }^{48}$

Este es el primer conflicto territorial que se presentó entre estas dos provincias, entre los años de 1853 a 1875, donde estaba en disputa el entonces distrito de Majagual, a quien Mompox quería adjudicarse, perteneciendo éste, a la provincia de Magangué según los decretos estipulados. ${ }^{49}$ Sin embargo, este conflicto les permitía a los habitantes de dicho distrito evadir los impuestos, puesto que cuando se les pedía informe sobre las rentas, ellos respondían con respuestas evasivas, declarando que ya le habían rendido cuentas a los de la provincia de Mompox. De esta manera, aprovecharon los vecinos de este distrito para evadir el pago de impuestos, y quién sabe si también se aprovecharían de dicha situación para incurrir en la práctica del contrabando con otras provincias vecinas, que es lo más probable que haya pasado.

Pero ¿Por qué le interesaba tanto al gobernador de Mompox este distrito? Primero, porque era el distrito más alejado de ambas cabeceras provinciales, en donde había, por ende, poca influencia de la autoridad de la recién creada provincia de Magangué. Esto le permitía a los gamonales y caciques momposinos inmiscuirse en el distrito sin que por ello se dieran cuenta fácilmente los magangueleños y hacer política local ahí.

Además hay que tener en cuenta, en segundo lugar, que el Distrito de Majagual siempre había mantenido relaciones con las personalidades del extinguido departamento de Mompox, al que en antaño siempre perteneció, a los cuales conocía. De ahí la fácil intromisión y manipulación de los momposinos a los vecinos de Majagual para entorpecer el funcionamiento de sus rivales al interior del distrito. Este entorpecimiento se manifiesta en la expresión que lanza el gobernador de Magangué en su carta, la que es importante volver a recalcar: “...al hacerse como debe

48 Se ha tratado de conservar la ortografía del original por eso nuestras notas aclaratorias van entre [ ]. Ver: AHC, manuscritos, Sección distritos y municipios, FG, Legajo $\mathrm{n}^{\circ}{ }_{13}$, años 1842-1865.

49 AHC, Gaceta Oficial del Estado Soberano de Bolívar, Cartagena, marzo de 1860. 
a aquellos empleados i manejadores de rentas serias esijencias se evaden con respuesta evacivas, diciendo dieron cuenta de su manejo á aquellas autoridades porque asi selo previnieron" los momposinos. Al respecto de estas cuestiones, Sergio Paolo Solano, Roicer Flórez y Willian Malkún señalan que,

La falta de autoridad, determinó que esta fuera ejercida, primordialmente, por gamonales y caciques, provocando una ruptura en el vínculo que unía a los ciudadanos con el Estado [en este caso con la provincia] ya que para muchos habitantes, la autoridad y las leyes que acataban eran las impuestas por aquellos, como fue la de adoptar la costumbre de que siempre que a algunos de ellos no le convenía la presencia de algún individuo en el lugar de su residencia, se le participaba la orden de marcha, se le aplicaba una paliza por pronto correctivo o se hacía "un no lo queremos", que consistía en reunir a una partida del pueblo, embriagarla y con cumbiamba [...] se arrojaba del lugar públicamente al excomulgado... ${ }^{50}$

Esto se debe, además, debido a que, como lo argumenta Sergio Paolo Solano, estas comarcas tenían todas las características sociales, económicas y políticas de los territorios de frontera, en donde "la ausencia del poder estatal institucional es asumida por formas de poder más informales pero no por ello menos efectivas”. ${ }^{51}$

$\mathrm{Y}$ en tercer lugar, porque Majagual era un distrito bastante poblado. Entre 1857 a 1860, la población de Majagual fue casi de la misma proporción que la de Magangué. 52 Factor por el cual lo pretendían ambas provincias. Ya que, a mayor concentración de población, vamos a encontrar mayor número de vecinos que contribuyan con los impuestos del Estado. En 1865, por ejemplo, se hizo en Majagual la segunda recaudación de la provincia de Magangué, con un total de \$547,09 y en

50 S. P. Solano, R. Flórez y W. Malkún, “Ganaderos y comerciantes”, p.33.

51 Sergio Paolo Solano, "Notas para un debate sobre el significado de la ganadería en la historia de la región caribe colombiana", en El Taller de la Historia n. ${ }^{\circ}$, Cartagena, Universidad de Cartagena, 2011, pp.161-190.

52 AHC, manuscritos, FG, Sección distritos y municipios, Legajo n. ${ }^{\circ} 13$, años 1842-1865; AHC, Gaceta Oficial del Estado Soberano de Bolívar, Cartagena, Octubre 9 de 1859; AHC, Gaceta Oficial del Estado Soberano de Bolívar, Cartagena, Marzo de 1860. En el censo de 1870 Majagual es el distrito de la provincia de Magangué que más habitantes tiene, alcanzando una población de 4730 habitantes, ver: BLAA, Gaceta de Bolívar, Cartagena, febrero 5 y mayo 9 de 1871. 
1873 también se hizo ahí la segunda recaudación de la provincia, la que fue de $\$ 1085,00.53$

Como habrá podido advertir el lector, este conflicto no pasó de ser un mero percance, pues porque Majagual siguió perteneciendo a la provincia de Magangué durante todo nuestro periodo de estudio. Sólo en 1865 vuelve a traslucir esa idea, en donde los vecinos del distrito, quizás impulsados por los momposinos, solicitan a la Asamblea del Estado que su territorio sea anexionado al de la provincia de Mompox. ${ }^{54}$

Por otra parte, en 1868 la Asamblea Legislativa del Estado expidió una ley sobre división territorial. El artículo tercero de la fijada ley de 3 de Diciembre señalaba:

Segréganse del distrito de Talaigua, provincia de Mompox, la parte oriental del rio Cauca, desde la boca del rio Cicuco hasta el punto fronterizo de la boca de Ojo-largo y se agrega a la de Magangué en los términos siguientes:

$1^{\circ}$ de la boca del rio Cicuco hasta caño angosto, al distrito de Yatí; $2^{\circ}$ desde caño angosto hasta la boca del caño Chicagua, al distrito de Magangué; y $3^{\circ}$ desde la boca del caño Chicagua hasta la boca de Ojo-largo, por ambas vías a San Sebastián de Madrid. ${ }^{55}$

Tras la aparición de este decreto resurgieron los conflictos territoriales entre dichas provincias puesto que se estaba desmembrando, aún más, la provincia de Mompox. Ya que, este era un importante espacio, tanto para el distrito en mención como para la provincia, como lo veremos más adelante en el transcurso de este caso. Contra tal decreto protesta el gobernador de los momposinos nueve meses después de haber sido pronunciada dicha ley. En su informe de 1869 proclamaba que:

53 BвC, Gaceta de Bolívar, Cartagena, marzo 25 de 1865; Gaceta de Bolívar, Cartagena, noviembre 28 y 30 de 1873 .

54 BвC, Gaceta de Bolívar, Cartagena, septiembre 27 de 1866.

55 Esta ley no fue publicada en la Gaceta. Pero si el decreto de 5 de diciembre de 1868, ver: AHC, Gaceta de Bolívar, Cartagena, septiembre 26 de 1869. 
Mui quejosos están los distritos de Pinillos i Talaigua de la Asamblea que expidió la ley de 3 de Diciembre de 1868, "adicional i reformatoria de las de división territorial”, que, aunque no aparece publicada hasta ahora, ha surtido sus efectos con el decreto de 5 de Diciembre del mismo año, dictado por el Poder Ejecutivo en su ejecución. La parte segregada de dichos distritos i agregada a la provincia de Magangué comprende una agregación que gustosa pertenecía a ésta provincia i con cuyo auxilio apenas podía atender el Distrito de Pinillos a sus gastos más precisos, i además están ubicados en esa parte, los únicos terrenos de que podían disponer los vecinos de Talaigua para sus crías de ganado vacuno i de cerda. Mas hoy, aparte del descontento en los habitantes de esas agregaciones con pertenecer a otra provincia, parece que se ejerce sobre ellos violencia obligándolos a pagar una suma para cubrir ciertos gastos hechos, según dicen, en la confección de la ley citada; cuando esos habitantes no habían pensado siquiera en ella. Finalmente, ese territorio segregado hoy de Mompox, está dividido con Magangué por el rio Cauca, que ha sido siempre el límite de dichas provincias, i temo que habiéndose sustituido esa demarcación por otra complicada i confusa, sea esto con el tiempo motivo de serias desavenencias. Reconociendo estas verdades i autorizado como estoy por vecinos de Pinillos i Talaigua para solicitar del Poder Ejecutivo se sirva pedir a la próxima Asamblea la derogatoria de dicha ley, lo hago hoy de la manera más formal i respetuosa. 56

En esta reclamación podemos encontrar cuatro argumentos que presenta el gobernador momposino para que se le devuelvan esos territorios. El primero de ellos corresponde a que el distrito de Pinillos se beneficia directamente de esos terrenos segregados para solventar los gastos que demandaba. Lo cual generaba preocupación al gobernador, ya que Pinillos tenía la cualidad de ser uno de los distritos más pobre de la provincia, por lo tanto, no tendría como pagar los impuestos. Por ejemplo, de los $\$ 7974,02$ que se recaudaron en la provincia, ahí solo se recaudaron $\$ 138,10$ y de los $\$ 815$ que se recaudaron en la provincia por las licencias para la venta por menor de aguardiente, en Pinillos sólo se recolectaron $\$ 67.57$

En segundo lugar, observamos que estas tierras servían para que los vecinos de Talaigua criaran sus ganados. Esta es, tal vez, la razón más significativa para el descontento, puesto que la ganadería era una de las ramas de la esfera económica que más auge tenía en ese momento y que demandaba el mercado. Por lo tanto, si

\footnotetext{
56 AHC, Gaceta de Bolívar, Cartagena, septiembre 26 de 1869.

57 AHC, Gaceta de Bolívar, Cartagena, julio 31 de 1870.
} 
le suprimían esos terrenos estarían disminuyendo el patrimonio de los vecinos ganaderos del distrito en mención.

En tercer lugar, el gobernador arguye que, al parecer, los magangueleños ejercen violencia sobre los habitantes de esas agregaciones al momento de cobrar los impuestos que expresa la ley. De hecho, podría suponerse que esta violencia se practicaba porque los habitantes de esas agregaciones se rehusaban a pagar los impuestos o era que cuando pertenecían a la provincia momposina no pagaban ninguna clase de impuesto, claro que sí. Por ende, se les debía excitar a que pagaran dicha contribución. Lo único nuevo era que pertenecían a otra provincia.

Y en cuarto lugar, muestra el problema de los límites territoriales, puesto que la división entre dichas provincias siempre había sido el rio Cauca, como bien lo señala el gobernador. Entonces, esta nueva ley representaría un problema ya que reinaría la confusión en dichas provincias al no saber con claridad los límites de ambas. Esta confusión serviría, además, como excusa para que los vecinos evadieran los impuestos, así como lo hicieron años atrás los vecinos de majagual.

Algo interesante de esta carta, es la forma como se despide el gobernador de la provincia de Mompox, Antonio G. Ribón, de una forma, tal vez, amenazante: “...autorizado como estoi por vecinos de Pinillos i Talaigua para solicitar del Poder Ejecutivo se sirva pedir a la próxima Asamblea la derogatoria de dicha lei, lo hago hoi de la manera mas formal i respetuosa". Es decir, que si no se le devuelven esos territorios ¿a qué mecanismos acudirá? ¿A las vías de hecho? ¿A sus influencias políticas? Esta última sería la estrategia que utilizaría para echar atrás esa ley. Recordemos que este gobernador pertenece a una de las familias más influyentes del Estado, y mantenía diversos lazos de amistad con el presidente del Estado, Manuel Amador Fierro, por lo tanto se le es fácil acudir a sus redes clientelares para lograr dicho fin. Tal como sucedió el año posterior. El artículo $1^{\circ}$ de la ley del 29 de octubre de 1870 así lo establecía: "se hacen las siguientes reformas en la división política de la provincia de Mompox: [...] las islas [...] que se encuentran cercanas a la ribera oriental del cauca hasta el punto denominado 'los tobillos', pertenecen al distrito de Talaigua". ${ }^{58}$ Con este artículo se le devolvieron los terrenos que habían sido segregados de la provincia.

58 AHC, Gaceta de Bolívar, Cartagena, Noviembre 6 de 1870. 
No obstante, la respuesta de los vecinos de la Provincia de Magangué no se hizo esperar. En 1871, Antonio G. Ribón, que oficiaba aún como gobernador de la provincia momposina, presenta en su informe de ese año al Secretario del Estado, la siguiente declaratoria con respecto a esos mismos territorios, que vale la pena citar en extenso:

Varios vecinos de la provincia de Magangué llamándose no sé por qué, vecinos también de la de Mompox, representaron a principios de presente año a mi despacho asegurando que en los caseríos del territorio comprendido entre los distritos de Pinillos i Talaigua, por la banda derecha del rio Cauca, no había autoridades públicas locales i que, tan mal aseguradas, podían correr peligro sus vidas i propiedades; otra representación más o menos en los mismos términos elevaron al poco tiempo al Poder Ejecutivo, i colocando en la necesidad de resolver el punto, pedí, como era mi deber, prontos informes a los alcaldes de aquellos dos distritos que me fueron dados en estos o semejantes términos.

$1^{\circ}$ que los expresados caseríos están regidos por los empleados públicos correspondientes;

$2^{\circ}$ Que sus habitantes son tan humildes i pacíficos que no tienen contra ellos quejas ni denuncio alguno;

$3^{\circ}$ Que si acaso dejaron de tener autoridades, fue durante el año de 1869 en que pertenecieron a la provincia de Magangué, después de haber sido segregados de la de Mompox por la ley de 3 de Diciembre de 1868, "adicional i reformatoria de la división territorial”, el que vino abajo por la razones expuestas en mi penúltimo informe, apoyadas por el Poder Ejecutivo i consideradas i admitidas por la Asamblea legislativa en sus sesiones de Diciembre de 1869; i

$4^{\circ}$ Que la reclamación de Magangué no tiene otro objeto sino cohonestar su insistencia en las próximas sesiones de la Asamblea para poseer nuevamente dicho territorio.

En 27 de junio último resolví definitivamente, por las anteriores exposiciones, archivar el citado memorial dando cuenta al Poder Ejecutivo.

A propósito de esto, recuerdo que los otros vecinos de Magangué que tienen algunas propiedades en aquel territorio, no aparecen firmados el memorial que me he ocupado, cosa que extraño, porque si los hechos denunciados fueran ciertos, a ninguno le convendría influir para que se corrigieran más que a ellos. ${ }^{59}$

Lastimosamente no contamos con la información del memorial que presentaron los vecinos de Magangué para distinguir los firmantes y conocer las verdade-

59 AHC, Gaceta de Bolívar, Cartagena, septiembre 3 de 1871. 
ras aspiraciones de los mismos, pero podemos establecer -de acuerdo a la evolución que había tenido dicho conflicto- que el verdadero interés de los vecinos de la mencionada provincia era lograr que se les devolvieran los terrenos que anteriormente le habían pertenecido. Puesto que, según Ribón, los vecinos de Magangué que tenían propiedades en ese territorio no firmaron el memorial, además, porque en el cuarto punto de sus argumentos así lo plantea.

Nótese, además, la astucia e inteligencia del gobernador, Antonio G. Ribón, al emanar los argumentos expuestos en contra de los de Magangué. De hecho, cuando los magangueleños reclaman y denuncian que en esos territorios: “...no había autoridades públicas locales i que, tan mal aseguradas, podían correr peligro sus vidas i propiedades", frente a dicha conjetura él manifiesta en su primer argumento que en esos caseríos si había el personal correspondiente y en su tercer punto "que si acaso dejaron de tener autoridades, fue durante el año de 1869 en que pertenecieron a la provincia de Magangué, después de haber sido segregados de la de Mompos...”. Entonces la lógica del gobernador momposino fue la de contradecir los argumentos de los de la provincia magangueleña para evitar que le volvieran a segregar esos territorios.

En 1873 este conflicto tomó otra dirección, ya que la lucha por esas tierras pasó de ser un conflicto diplomático, a uno en el "campo de batalla". Todo ocurrió cuando

El Señor Luis M. Larios, alcalde del distrito de Pinillos en la provincia de Mompos, invadió el territorio de esta provincia en la noche del dia 5 del presente mes, a la cabeza de una turba de hombres armados de lanzas, escopetas i machetes, i procedió a aprisionar al señor Juez de esta provincia, que a la sazon se dirijía a practicar el deslinde de unos terrenos, a su Secretario, Sr. J. M. Bustos, al apoderado del resguardo de Guazo Sr. Catalino Bonilla i al Sr. Felipe Martinez Romero que los acompañaba, i habiendo maltratado gravemente a este último, los consignó a todos en la carcel de Piníllos, en donde permanecieron toda esa noche, expuestos a los ataques e injurias de una multitud desenfrenada, hasta el siguiente dia 6, en que lograron se les pusiera en libertad. 60

60 “Informe anual del Gobernador de la provincia de Magangué, en AHC, Gaceta de Bolívar, Cartagena, octubre 25 de 1873 . 
Este suceso lo denuncia Manuel Drago, gobernador de la provincia de Magangué, y muestra la situación a la que estaban sometidos los habitantes de estas provincias debido a la confusión que había en los límites interprovinciales. De ahí que, sea necesario hacernos los siguientes cuestionamientos ¿quién estaba invadiendo a quién? Porque el hecho de que haya sido el gobernador de Magangué quien puso la queja no quiere decir que fueron los momposinos quienes realmente invadieron aquella provincia, puesto que, si estos reaccionaron de esa forma al deslinde que estaban haciendo los de la provincia de Magangué, puede ser, porque eran estos quienes estaban invadiendo el territorio de aquellos. Además, ¿Por qué tenía que ser en la noche ese deslinde? por algo bueno no era.

Por otro lado, esta situación nos permite entender que, de una u otra forma, el conflicto entre estas dos provincias - por esos terrenos- se debía a que estos eran territorios del resguardo de Guazo, de la provincia de Magangué y como tal era apetecido por las elites del Estado (muchos de los cuales eran ganaderos), por ser tierras ricas en producción. Este resguardo libraba un conflicto alterno, debido a la promulgación de la constitución de 1863, que bajo un doctrinarismo liberal demandaba la individualización e igualdad de las personas y la liberación de la propiedad. Esto lo aprovecharon las elites y usaron toda clase de discursos y mecanismos para suprimir los resguardos y apoderarse de esas tierras, pero los indígenas utilizaron diversas estrategias y mecanismos para defenderlos y evitar su expropiación. 61

Las dos importantes estrategias de los indígenas del resguardo de Guazo fueron, en primer lugar, organizar la "Sociedad de indígenas de Guazo" con la cual pretendían "favorecer momentáneamente a la comunidad de la forma que se ha reunido para oponerse a las miras de los que pretenden usurpar sus derechos" $62 \mathrm{y}$, en segundo lugar, consolidar las relaciones con políticos influyentes en el Estado, como sucedió con Manuel Amador Fierro al que nombraron su abogado dos años después de crear la "Sociedad de indígenas de Guazo". ${ }^{63}$ De esta forma, los indígenas libraron varios enfrentamientos diplomáticos con algunas personalidades de la

61 Roicer Flórez, "Indígenas y ciudadanía en el Estado Soberano de Bolívar, 1863-1875”, en Historia y Sociedad n. ${ }^{\circ} 16$, Medellín, Universidad Nacional, 2009, pp.49-72.

62 AHC, Manuscritos, Sección Hacienda [SH], FG, Caja n. ${ }^{\circ}$ 23, Abril 3 de 1873.

63 BвC, Diario de Bolívar, Cartagena, julio 15 de 1875. 
provincia para mantener sus tierras. ${ }^{64}$ Así como, actos de violencia manifestados en la carta antes citada.

La Asamblea Legislativa del Estado se percató de la problemática de la confusión que había en los límites entre las provincias de Magangué y Mompox sólo después que se habían presentado todos estos conflictos jurisdiccionales, en el año de 1873, cuando en la ley de 12 de Diciembre de 1873 expide el artículo 20 en donde autorizaba al Poder Ejecutivo,

... Para que nombre dos comisionados que examinen los territorios que actualmente limitan las provincias de Mompox i Magangué, i puedan informar sobre los límites que con mejor acuerdo deban establecerse en dichas provincias.

Con el informe de los comisionados de que trata este artículo, el Poder Ejecutivo informará lo conveniente sobre dichos límites a la próxima Asamblea, i mientras se decide por ésta definitivamente sobre los límites que dividen las expresadas provincias, se tendrán como tales, los que correspondan actualmente, según los caseríos o distritos que les están agregados conforme a las leyes vigentes..$^{65}$

Con este informe se buscaría establecer y llegar a un acuerdo conciliable sobre los límites que deberían tener ambas provincias para evitar todo tipo de confusión y nuevos conflictos jurisdiccionales entre estas.

\subsection{Conflictos políticos}

Los conflictos políticos que se presentaron entre estas provincias acaecieron porque, como ya hemos mencionado anteriormente, Mompox en su afán de volver a controlar y acaparar el poder político en la subregión momposina quería que se suprimiera la provincia de Magangué, por lo tanto hizo las veces para que se diera tal fin, pero los magangueleños usaron sus nexos y estrategias para proteger la provincia y evitar su abolición.

64 AHC, Manuscritos, SH, FG, Caja n. ${ }^{\circ}$ 23, junio 9 de 1873 y julio 29 de 1873.

65 AHC, Gaceta de Bolívar, Cartagena, Diciembre 23 de 1873. 
El primer intento de los momposinos por suprimir y, de paso, subordinar a la provincia de Magangué fue en el año de 1862 cuando los diputados por la provincia de Mompox presentaron un proyecto de ley donde proponen que la división del Estado debe ser reducida a un número menor que el actual. Este proyecto manifiesta:

Divídase el territorio del Estado en seis provincias que tomarán su nombre de las localidades que han de servir de cabecera, i que serán:

$1^{\mathrm{a}}$. Barranquilla...

$2^{\mathrm{a}}$. Carmen...

$3^{\mathrm{a}}$. Cartagena...

$4^{\mathrm{a}}$. Lorica...

$5^{\mathrm{a}}$. Mompos, compuesta de las actuales provincias de ese nombre i Magangué; i $6^{\mathrm{a}}$. Sincelejo...

Dada \& Presentado a la Asamblea legislativa del Estado en 10 de Diciembre de 1862 por los infrascritos diputados por la provincia de Mompox.

P.T. Esparragoza-P. Blanco García. ${ }^{66}$

Este proyecto, aunque fue presentado por dos de las personalidades más influyentes de la provincia de Mompox, Pedro Tiberio Esparragoza y Pedro Blanco García, no fue aprobado por la Asamblea. Ésta, al contrario, dieciséis días después proclamó una nueva ley sobre organización territorial que reafirmó a la provincia de Magangué como una de las doce del Estado que estaban incluidas en esa nueva división. ${ }^{67}$ Además, el presidente del Estado tenía cierta estimación por esta provincia. ${ }^{6}$

Siete años después los momposinos se seguían oponiendo a la existencia de la provincia de Magangué, por esas razones las autoridades y los notables de esta provincia se vieron obligados a ejercer maniobras de defensa para salvaguardar la existencia de la misma. Por eso, M. J. Camargo, gobernador de la provincia argumentaba que:

\footnotetext{
66 BBC, Gaceta Oficial del Estado Soberano de Bolívar, Cartagena, diciembre 14 de 1862.

67 BвC, Gaceta Oficial del Estado Soberano de Bolívar, Cartagena, diciembre 28 de 1862.

68 "Mensaje del gobernador del Estado de Bolívar, a la asamblea legislativa en sus sesiones ordinarias de 1858", en AHC, Gaceta Oficial del Estado de Bolívar, Cartagena, Octubre $1^{\circ}$ de 1858.
} 
...hay algunos mal intencionados, que desean la eliminación de ésta provincia, a ello se ha propendido más de una vez, pero no es de esperarse que los dignos Legisladores del Estado den jamás cabida a semejante a proyecto tan antipatriótico como injusto. Los pueblos no son humildes siervos a quienes se les puede tan pronto conceder como arrebatar por capricho, su entidad territorial. 69

Los "mal intencionados" a quienes hace referencia el gobernador eran sin duda los momposinos que en su afán de acaparar el poder político buscaron la pronta eliminación de la provincia de Magangué. De esta manera aumentarían sus influencias y ejercerían deliberadamente en la subregión los diferentes poderes (económico, político, social e ideológico). ${ }^{70}$ Pero al igual que las veces anteriores esto no se le pudo cumplir porque Magangué siguió siendo provincia hasta bien entrado el siglo XX.

\subsection{Conflictos económico-comerciales}

Los conflictos económicos que acontecieron entre estas dos provincias fueron de dos clases, los primeros, ya los hemos tratado anteriormente concernientes a los acaparamientos de tierra que querían ejercer las provincias sobre los territorios donde no eran definidos con claridad los límites jurisdiccionales. Los cuales también podríamos establecer como económicos, basándonos en la tesis de quien tiene más tierra, tiene más poder. Los segundos, son los que trataremos a continuación concernientes a las disputas comerciales que había entre dichas provincias, ya que Mompox no sólo quería retomar el control político de la zona, sino también el comercial. Por ende fue que se empecinaron en intentar volver el curso del rio hacia su destino natural, que era el brazo de Mompox. ${ }^{71}$

69 "Informe anual del Gobernador de la provincia de Magangué", en AHC, Gaceta de Bolívar, Cartagena, septiembre 12 de 1869.

70 Nestor Miranda, Clientelismo y dominio de clase. El modo de obrar político en Colombia, Bogotá, Cinep, 1970, p.22.

71 BBC, Gaceta de Bolívar, Cartagena, Marzo 25 de 1866; "Informe anual del Gobernador de la provincia de Mompox", en AHC, Gaceta de Bolívar, Cartagena, agosto 31 de 1867; Gaceta de Bolívar, Cartagena, septiembre 26 de 1869; Gaceta de Bolívar, Cartagena, septiembre 3 de 1871. 
Algunas veces no vieron otra salida que atentar contra la principal fuente de ingreso de su provincia rival "las ferias comerciales" que se celebraban tres veces al año en Magangué. Por eso siempre existió la desconfianza de los gobernantes de esta provincia ante la concurrencia de los momposinos a la feria. Rafael González, gobernador de la provincia en 1860 manifestaba su preocupación en un fragmento de una carta enviada al Secretario General del Estado, que dice: "Siendo lo mas notable que ni siquiera una riña en que hubiera resultado herida [la feria], cuando esto con razón se temía por la reunión de tantos momposinos que tan mal se quieren ellos mismos". ${ }^{72}$ En 1870 el gobernador de dicha provincia, Clemente Canabal, pronunciaba en su informe la misma preocupación, mostrando que,

En la feria de junio, no dejaron de sentirse entre el comercio i la generalidad, rumores de que podía alterarse el orden público; por cuya sospecha, instantáneamente pretendióse paralizar la marcha de las transacciones mercantiles; pero mi autoridad, puesta en acción, desbarato aquellas preocupaciones, brindándoles la paz i la seguridad públicas sostenidas por la opinión de que gozo.73

Con respecto a lo anterior, Antonio G. Ribón, gobernador de Mompox en ese mismo año, se encontraba descontento porque

...por desgracia hay en él [Estado] hombres que estimando en poco la tranquilidad pública i estimulados por el bastardo deseo de medrar a la sombra de la revueltas, ajitan i azuzan a un puñado de chafaroteros que descontentos como ellos con la paz de los pueblos, porque no les deja los bienes ni los goces que la guerra les brinda, se prestan gustosos, a la menor insinuación, a entrar en la vía de los desórdenes i de los crímenes, con el pretexto de derribar gobiernos, aunque para ello no haya motivo alguno justificado [...] fue por esto que en la feria de Magangué, a fines de junio último, se temiera no una revolución, porque no había motivos ni elementos para hacerla, sino un alboroto o asonada... ${ }^{74}$

72 AHC, Manuscritos, Sección provincias, FG, Caja n. ${ }^{\circ} 38$, Cartagena, junio 16 de 1860.

73 AHC, Gaceta de Bolívar, Cartagena, agosto 7 de 1870.

74 "Informe anual del Gobernador de la provincia de Mompox", en AHC, Gaceta de Bolívar, Cartagena, julio 31 de 1870 . 
Al parecer, el gobernador de Mompox estaba defendiendo la feria. Ya que ésta era de interés general para el fisco del Estado. Pero, además, para mantener las buenas relaciones con las demás elites del Estado. Y para evitar los rumores de que los revoltosos en la feria eran los momposinos. Ya que, los que estaban armando la revuelta, al parecer, eran el General Manuel Martínez y José María Mendoza Llanos.

Otra manera en que se podrían presentar este tipo de conflictos era cuando se presentaban los movimientos comerciales, esto es, cuando vendían sus productos en una ciudad y aducían, por el contrario, que habían pagado los impuestos comerciales en la otra ciudad. De esta situación daba cuenta, Antonio G. Ribón, en su informe de 1869 cuando señalaba:

Es verdad que muchas veces ha tenido noticias el administrador de Hacienda de haberse introducido en ésta plaza un número de cargas de tabaco, pero no ha podido hacer efectivo el derecho de dos i medio centavos ( 2 1/2 cs.) por kilogramo, por haberle presentado el introductor guía expedido en la administración de Hacienda de Magangué. No sé cómo siendo dicha ciudad un punto de tránsito para el tabaco que de Ambalema ha venido a ésta plaza, se haya pagado allí el derecho correspondiente para dejar de pagarlo en Mompox, que ha sido el lugar de consumo. ${ }^{75}$

Esta situación, internamente lleva un agudo matiz de contrabando, y debido a esa circunstancia fue que en 1863 se presentó un desencuentro entre comerciantes de Mompox, que, al parecer, no pagaron el impuesto comercial en Magangué. En este conflicto se vieron envueltos importantes comerciantes de la provincia de Mompox, tales como, Sabas Martínez Troncoso, Pedro Vásquez, Andrés SantoDomingo Vila y el gobernador momposino de la provincia de Magangué Pedro Laza Grau, a quien se le acusaba de haberse "vendido [...] por la suma de seiscientos pesos, dando lugar con esto i otros hechos a que los comerciantes lo titularan ' $\mathrm{el} \mathrm{Go-}$ bernador salteador de ferias"; pero según el administrador de hacienda de Magangué, Pedro Argumedo, realmente fueron $\$ 604,12^{1 / 2}$ centavos que fueron destinados, supuestamente, al tesoro del Estado. ${ }^{76}$

75 AHC, Gaceta de Bolívar, Cartagena, septiembre 26 de 1869.

76 BвC, Gaceta Oficial del Estado Soberano de Bolívar, Cartagena, Noviembre 15 de 1863. Cursivas en el original. 


\section{A manera de conclusión}

Para la segunda mitad del siglo XIX Mompox tuvo que afrontar el auge que tomó magangué. La villa momposina entró en un marcado estancamiento económico en este periodo. Por lo que tuvo que ceder espacios de poder a Magangué, luego de haber sido creada la provincia de ese nombre. En consecuencia se reconfiguraron los viejos conflictos que existían entre estas ciudades, ya que a Mompox se le suprimió gran parte de su territorio que fue anexionado a la recién creada provincia y los límites entre estas siempre fueron confusos durante el periodo estudiado. Entonces, su elite, inició todo un proceso de políticas destinadas a recuperar, no solo el territorio perdido, sino también el poder político y económico que durante mucho tiempo había ejercido en la zona.

En ese orden de ideas, los conflictos que presentaron estas dos provincias fueron característicamente territoriales, políticos y económicos. Los cuales tuvieron como trasfondo la lucha por el poder o por los poderes (político, económico y social) en la depresión momposina. En muchos casos estos conflictos eran empezados por alguno de los actores sociales más pudientes de la provincia quienes se valían de su influencia política y económica para buscar encarar los conflictos.

Es decir hacían uso del poder del que estaban investidos para atacar a la otra provincia, o en su defecto para defenderse o defenderla. A través de sus nexos clientelares, familiares, matrimoniales, económicos, de partido, de amistad, etc., que les permitía instaurar alguna reclamación o defenderse de alguna acusación, esto es, se escudaban detrás de sus redes para hacer cualquier reclamo, protesta, petición, o para defender sus intereses personales, clientelares y los de la provincia. Lo anterior se evidencia a través de cartas, informes, memoriales, etc., que dejaron nuestros sujetos históricos.

La diplomacia jugó un papel importante a la hora de la resolución de un conflicto. Ya que la mayoría de estos se confeccionaban en las oficinas, casas y haciendas de las personalidades provinciales y ahí se resolvían. Pero hubo momentos en los que la diplomacia pasó al campo de batalla o al terreno en disputa, en donde muchos se enfrentaron por defender los intereses de aquellos que acaparaban el poder y que en últimas eran los verdaderos beneficiados en estos conflictos. Hemos de suponer que se valían del analfabetismo y pobreza que caracterizaba a la mayoría de las per- 
sonas de estas provincias para manipularlos. $\mathrm{Y}$ a las relaciones que establecían con pequeños y medianos productores de las comarcas más apartadas de la provincia para ejercer influencia político-social en ellos.

Muchas de estas personalidades fueron comerciantes, ganaderos agricultores, hacendados, o combinaban varias de estas actividades, pero rara vez se le vio actuando en la vida política local o regional. Tal vez, porque no les quedaba tiempo, no querían hacerlo o porque eran analfabetas. Sin embargo, estaban conectados con las redes políticas y económicas de la provincia y ayudaban o se veían afectados por las cuestiones políticas de la misma. Entre ellos encontramos a Cayo G. Ribón, Oscar A. Trespalacios, Tomas Alvarado, Santiago Álvarez, Buenaventura Caro,77 Manuel Martínez González, Manuel Villalobos, Benito Pontón, Pedro Cerpa, Manuel García Ardébol, Jorge Delgado, Ezequiel Cordero, entre otros. ${ }^{78}$

Por otra parte, en estas provincias hubo un papel activo de las mujeres que merece una investigación más exhaustiva. Muchas de estas fueron grandes ganaderas, comerciantes, agricultoras y hacendadas y algunas debieron actuar en la política local, aunque no tenemos indicios directos pero si insinuaciones de que lo hubieran hecho, además, porque eran madres de muchos de esos "nuevos políticos" que florecieron en estas provincias y esposas y/o viudas de otros.

Algunas de las más destacadas matronas de estas provincias fueron: Lucia Viñas de García, María Josefa Bustos, Benedicta Riano, Martina Cantero, Manuela Barrera, entre otras. ${ }^{79}$ Manuela Barrera es quien ilustra mejor este caso. Era una mujer con gran poder económico e influencia en la provincia de Mompox y en el Estado: madre del clan Obeso. En Enero de 1868 le conceden una licencia para destilar y rectificar aguardientes, pero meses después de habérsele concedido dicha licencia, la alberca destinada a tales oficios se le rompió, ante esta situación ella pide al Poder Ejecutivo que se le exima de pagar el impuesto sobre aguardiente, ya que no está “...obligada a pagar el derecho de patente hasta que la fábrica en referencia se encuentre en ejercicio, que será sin falta alguna el $10^{\circ}$ de Octubre próximo”. Más adelante argumenta,

77 BBC, Gaceta de Bolívar, Cartagena, octubre 1 de 1868.

78 BBC, Gaceta de Bolívar, Cartagena, Agosto 23 de 1868.

79 BBC, Gaceta de Bolívar, Cartagena, octubre $1^{\circ}$ y 11 de 1868. 
Mi petición es justa, Ciudadano Presidente, porque si es verdad que el derecho expresado se causa destilando i rectificando el aguardiente con las condiciones que establece la lei, dicho derecho no puede tener lugar aun subsistiendo la licencia correspondiente, cuando por una fatalidad inesperada o no prevista, llega a imposibilitarse la destilación. ${ }^{80}$

El mes de julio se resolvió la situación en el juzgado de la provincia, en donde fueron a declarar, a petición de la señora Barrera, algunos vecinos momposinos entre ellos Pantaleón German Ribón. Así, la Asamblea terminó aprobando dicho reclamo a favor de la agraviada.

\section{Bibliografía}

\section{Fuentes primarias}

Archivo Histórico de Cartagena (AHC).

Biblioteca Bartolomé Calvo (BBC).

Biblioteca Luis Ángel Arango (BLAA).

\section{Fuentes secundarias:}

Balmaseda, Francisco J, “La feria de Magangué”, en Boletín Historial, n. ${ }^{\circ}$ 45-46, Cartagena, Academia de Historia de Cartagena, 1919.

Burke, Peter, Venecia y Ámsterdam. Estudio sobre las elites del siglo XVII, Barcelona, Gedisa Ed., 1996.

Falcón, Romana, "Un diálogo entre teorías, historias y archivos", en Romana Falcón (coord.), Culturas de pobrezas y resistencia. Estudios de marginados, proscritos y descontentos México, 1804-1910, El Colegio de México/Universidad Autónoma de Querétaro, 2005, pp.11-42

Fals Borda, Orlando, Historia doble de la Costa. Mompox y Loba, Bogotá, Universidad Nacional de Colombia, 2002.

80 BBC, Gaceta de Bolívar, Cartagena, octubre 11 y diciembre 6 de 1868. 
Fals Borda, Orlando, El Presidente Nieto, Bogotá, Universidad Nacional/Banco de la República/El Áncora Eds., 2002.

Flórez, Roicer, "Caña de azúcar y aguardiente en el Estado Soberano de Bolívar, 18571886”, en Cuadernos de Desarrollo Rural n. ${ }^{\circ} 6$, Bogotá, Universidad Javeriana, 2009, pp.35-57.

Flórez, Roicer, “Indígenas y ciudadanía en el Estado Soberano de Bolívar, 1863-1875”, en Historia y Sociedad n. ${ }^{\circ}$ 16, Medellín, Universidad Nacional, 2009, pp.49-72.

Garrido, Margarita, Reclamos y representaciones. Variaciones sobre la política en el Nuevo Reino de Granada, 1770-1815, Bogotá, Banco de la Republica, 1993.

Guerra, François-Xavier, "Lugares formas y ritmos de la política moderna”, en Boletín de la Academia Nacional de la Historia n. ${ }^{\circ} 285$, Caracas, Academia de la Historia de Venezuela, 1989.

Gutiérrez, Alicia, Las prácticas sociales: una introducción a Pierre Bourdieu, Madrid, Tierradenadie, 2002.

Jiménez, Orian y Pérez, Edgardo, La Mojana: medio ambiente y vida material en perspectiva histórica, Medellín, Universidad de Antioquia, 2007.

Meneses Urzola, José, Presencia e influencia italiana en Colombia: El caso de Magangué, 1890-1930. Redes sociales y circuitos comerciales, Trabajo presentado para optar al título de Historiador, Universidad de Antioquia, 2009.

Miranda, Nestor, Clientelismo y dominio de clase. El modo de obrar político en Colombia, Bogotá, Cinep, 1970.

Miranda Gil, Eloy, Disputas territoriales, políticas y económicas entre las provincias de Magangué y Mompóx, 1853-1875, Cartagena, trabajo de grado para optar al título de historiador, Universidad de Cartagena, 2013.

Ocampo, Javier, Historia básica de Colombia, Bogotá, Plaza \& Janes Editores, Edición Actualizada, 2007.

Ocampo, Javier, “La patria Boba”, en Cuadernillos de Historia, Bogotá, Panamericana Ed., 1998.

Peñas Galindo, David y Arquez, Oscar, Espacio, poblamiento y sociedad en la región de la depresión momposina, Medellín, Ed. Lealón, 1994.

Posada, Carbó, El Caribe Colombiano. Una historia regional (1870-1930), Bogotá, Banco de la República/El Áncora Editores, 1998. 
Posada, Carbó, "Empresarios y ganaderos en la Costa Atlántica (1850-1950)", en Carlos Dávila (comp.), Empresas y Empresarios en la historia de Colombia. Siglos XIXXX. Una colección de estudios recientes, Bogotá, Ed. Norma, 2003, pp.61-81.

Roa Valdelamar, Cristian, Ferias comerciales de Magangué (1858-1902), Tesis para optar título de historiador, Universidad de Cartagena, 2002.

Salazar, Stella y Aldana, Eduardo, "Magangué en la encrucijada", en Fabio Zambrano (comp.), Poblamiento y ciudades del Caribe colombiano, Bogotá, Observatorio del Caribe Colombiano/Fonade/Universidad del Atlántico, 2000.

Solano, Sergio Paolo, "Empresarios, capitales e industrias en la región Caribe colombiana durante el despegue del modelo agroexportador a comienzos del siglo Xx", en $H$ industri@ n. ${ }^{\circ}$ 4, Buenos Aires, Universidad de Buenos Aires, 2009.

Solano, Sergio Paolo, "Notas para un debate sobre el significado de la ganadería en la historia de la región caribe colombiana", en El Taller de la Historia n. ${ }^{\circ}$, Cartagena, Universidad de Cartagena, 2011, pp.161-190.

Solano, Sergio Paolo, Flórez, Roicer y Malkún, William, "Ordenamiento territorial y conflictos jurisdiccionales en el Bolívar Grande 1800-1886”, en Historia Caribe n. ${ }^{\circ} 13$, Barranquilla, Universidad del Atlántico, 2008, pp.65-119.

Solano, Sergio Paolo, Flórez, Roicer y Malkún, William, "Ganaderos y comerciantes: el manejo del poder político en el Estado Soberano de Bolívar (Colombia), 18571886”, en Historia y Sociedad n. ${ }^{\circ}$ 18, Medellín, Universidad Nacional de Colombia, 2010, pp.15-42.

Striffler, Luis, El rio san Jorge, Cartagena, 1958.

Tovar, Hermes, "La historiografía sobre Cartagena de indias en el siglo XVIII", en Haroldo Calvo y Adolfo Meisel (eds.), Cartagena de indias y su historia, Cartagena, Universidad Jorge Tadeo Lozano, Seccional Caribe y Banco de la República, 1997.

Uribe Uribe, Carlos, Poblamiento y relaciones subregionales en el bajo magdalena: Brazo de Loba, 1770-19oo, Medellín, Tesis de Historia, Universidad Nacional, 2002.

Valle Porto, Alfonso del, Compendio monográfico de la villa de Magangué, Medellín, 1992.

Vérbel, Grey, "Elites y redes de poder en torno al proyecto regenerador. Cartagena, 18741892", en El Taller de la Historia n. ${ }^{\circ}$, Cartagena, Universidad de Cartagena, 2011, pp.41-62. 
Vones-Liebenstein, Úrsula, "El método prosopográfico como punto de partida de la historiografía", en Anuario de Historia de la iglesia n. ${ }^{\circ}{ }^{14}$, Navarra, Universidad de Navarra, 2005, pp.351-364. 